\title{
Can Esophageal Baseline Impedance Predict Proton Pump Inhibitor Response in Gastroesophageal Reflux Disease?
}

\author{
Kyoungwon Jung and Moo In Park ${ }^{*}$ \\ Department of Internal Medicine, Kosin University College of Medicine, Busan, Korea
}

Article: Esophageal baseline impedance reflects mucosal integrity and predicts symptomatic outcome with proton pump inhibitor treatment

Xie C, Sifrim D, Li Y, Chen M, Xiao Y

(J Neurogastroenterol Motil 2018;24:43-50)

Gastroesophageal reflux disease (GERD) is characterized by reflux of stomach contents and causes unpleasant symptoms and complications. Proton pump inhibitors (PPIs) are widely used to treat GERD and significantly reduce gastric acid secretion. ${ }^{1}$ However, despite PPI therapy, up to $40 \%$ of patients report persistent GERD symptoms. ${ }^{2}$ Some studies have attempted to predict which patients will have a poor response to PPI treatment. A recently published review article reported that poor response to PPI treatment is related to a PPI-metabolizer genotype, CYP, and requires combined adjunctive therapy. ${ }^{2}$ Adjusting treatment in patients with the PPI-metabolizer genotype or switching to a CYP2C19-independent PPI is a simple way to increase the PPI response. In addition, the use of adjunctive agents may be considered when the physiological mechanism of PPI nonresponse is suspected. $^{2}$

For such patients, recent research focused on whether the diagnosis is truly correct and the degree of treatment response can be predicted. According to the recent implementation of a
$\mathrm{pH}$ monitoring method combined with baseline impedance (BI), and depending on the degree of acid exposure and esophageal hypersensitivity highlighted in the Rome IV criteria for functional esophageal disorders, patients with suspected GERD with typical chest pain and regurgitation are divided into 4 subtypes: erosive esophagitis, non-erosive reflux disease (NERD), reflux hypersensitivity, and functional heartburn $(\mathrm{FH}){ }^{3}$ Especially when using mean nocturnal $\mathrm{BI}$ in the distal esophagus for patients with heartburn, several studies showed that the value of BI and degree of reflux showed a negative correlation and the mean BI level was statistically significantly lower in the PPI-responsive group than in the non-responsive group. ${ }^{4-6}$ Therefore, esophageal BI is used to predict the therapeutic effect of PPI related to severity of acid exposure. ${ }^{6-8}$ However, there is still insufficient evidence to standardize this strategy.

Along with the $\mathrm{BI}$, the concept of intercellular space diameter (ISD) has recently been studied. Histologically, dilated intercellular space (DIS) is frequently observed in GERD patients. In addition,

Received: December 13, 2017 Revised: None Accepted: December 19, 2017

(a) This is an Open Access article distributed under the terms of the Creative Commons Attribution Non-Commercial License (http://creativecommons. org/licenses/by-nc/4.0) which permits unrestricted non-commercial use, distribution, and reproduction in any medium, provided the original work is properly cited.

*Correspondence: Moo In Park, MD, PhD

Department of Internal Medicine, Kosin University College of Medicine, 262 Gamcheon-ro, Seo-gu, Busan 49267, Korea Tel: +82-51-990-5205, Fax: +82-51-990-5055, E-mail: mipark@kosinmed.or.kr 
histological examination of the site of non-erosive distal esophagitis was performed and the DIS score was semi-quantitatively evaluated. ${ }^{9}$ A previous study demonstrated that impairment of mucosal integrity involves an increase in cellular permeability, which is related to the presence of DIS and impaired mucosal integrity. ${ }^{10}$ Moreover, a study showed that these were functionally related to reduced BI levels, and were induced by acidic perfusion in rabbit models and healthy volunteers. ${ }^{11}$

If so, how much can the BI and ISD predict the degree of PPI treatment response? In this issue of the Journal of Neurogastroenterology and Motility, Xie et $\mathrm{al}^{12}$ tried to investigate the correlation with mucosal integrity using the esophageal BI level, which can be easily measured and can be used to determine whether these parameters can predict response to PPI. In this study, they confirmed that $\mathrm{BI}$ level is lowest in ERD and that BI levels were low in both ERD and NERD, as previously reported. ${ }^{4-9,12}$ In particular, in a comparison with the control group, the authors showed cut-off values for sensitivity and specificity of $55.4 \%$ and $100 \%$, respectively, based on $1764 \mathrm{ohm}$.

The results of this study were meaningful, not only for measurement of BI levels, but also to assess DIS by conducting tissue examinations at 2-4 cm from the esophagogastric junction. This result shows a cut-off value of $0.73 \mu \mathrm{m}$ in the intercellular space and can be used to distinguish the control group (sensitivity $78.3 \%$ and specificity $90 \%)^{12}$

In addition, this study showed that DIS and acid exposure time negatively correlated with BI. Furthermore, the simple clinical interpretation that checking $\mathrm{BI}$ levels alone could predict the therapeutic effect of a PPI without performing invasive tissue examination was a meaningful finding.

However, because $\mathrm{FH}$ as an important component of GERDrelated disease was excluded in this study, the relationship between $\mathrm{BI}$ and FH could not be confirmed. Moreover, compared with healthy controls, the study was not able to confirm the ISD difference in patients with $\mathrm{FH}$. Even though tissue examination for ISD was performed within $3 \mathrm{~cm}$ from the esophagogastric junction, a question remains as to whether a single histological examination can reflect all intercellular spaces. Since the group of patients with mild esophagitis (Los Angeles classification A and B) is relatively large and severe esophagitis is rarely included, it is not possible to determine the difference between DIS and BI depending on the severity of esophagitis. In addition, the results according to PPI responsiveness, the relatively high rate of loss to follow-up in the NERD group, the high proportion of esophageal hypersensitivity in the PPI failure group, and the lack of follow-up data for BI and intercellular space after PPI treatment were limitations of this study. This study had several additional limitations, as noted by the author: a small sample size completed the 8-week follow-up, the control group was young, and the relationship between symptom severity and the BI and DIS values was not investigated.

Nonetheless, it is interesting that a simple BI measurement method can distinguish between patients with heartburn and regurgitation and predict the response to PPI treatment. Thus, further larger-scale controlled studies are necessary.

\section{References}

1. Vakil N, van Zanten SV, Kahrilas P, Dent J, Jones R; Global Consensus Group. The Montreal definition and classification of gastroesophageal reflux disease: a global evidence-based consensus. Am J Gastroenterol 2006;101:1900-1920.

2. Hillman L, Yadlapati R, Thuluvath AJ, Berendsen MA, Pandolfino JE. A review of medical therapy for proton pump inhibitor nonresponsive gastroesophageal reflux disease. Dis Esophagus 2017;30:1-15.

3. Aziz Q, Fass R, Gyawali CP, Miwa H, Pandolfino JE, Zerbib F. Functional Esophageal Disorders. Gastroenterology Published Online First: 15 Feb 2016. doi: 10.1053/j.gastro.2016.02.012.

4. de Bortoli N, Martinucci I, Savarino E, et al. Association between baseline impedance values and response proton pump inhibitors in patients with heartburn. Clin Gastroenterol Hepatol 2015;13:1082-1088, e1081.

5. Ye BX, Jiang LQ, Lin L, Wang Y, Wang M. Reflux episodes and esophageal impedance levels in patients with typical and atypical symptoms of gastroesophageal reflux disease. Medicine (Baltimore) 2017;96:e7978.

6. Patel A, Wang D, Sainani N, Sayuk GS, Gyawali CP. Distal mean nocturnal baseline impedance on $\mathrm{pH}$-impedance monitoring predicts reflux burden and symptomatic outcome in gastro-oesophageal reflux disease. Aliment Pharmacol Ther 2016;44:890-898.

7. Jiang L, Ye B, Lin L, Wang Y, Wang M. Role of altered esophageal intraluminal baseline impedance levels in patients with gatroesophageal reflux disease refractory to proton pump inhibitors. Medicine (Baltimore) 2016;95:e4351.

8. Kohata Y, Fujiwara Y, Yamagami H, et al. Usefulness of baseline impedance in patients with proton pump inhibitor-refractory nonerosive reflux disease. J Gastroenterol Hepatol 2015;30(suppl 1):36-40.

9. Kandulski A, Weigt J, Caro C, Jechorek D, Wex T, Malfertheiner P. Esophageal intraluminal baseline impedance differentiates gastroesophageal reflux disease from functional heartburn. Clin Gastroenterol Hepatol 2015;13:1075-1081.

10. Weijenborg PW, Smout AJ, Bredenoord AJ. Esophageal acid sensitivity and mucosal integrity in patients with functional heartburn. Neurogastroenterol Motil 2016;28:1649-1654.

11. Farre R, Blondeau K, Clement D, et al. Evaluation of oesophageal mucosa integrity by the intraluminal impedance technique. Gut 2011;60:885892. 
12. Xie C, Sifrim D, Li Y, Chen M, Xiao Y. Esophageal baseline impedance reflects mucosal integrity and predicts symptomatic outcome with proton pump inhibitor treatment. J Neurogastroenterol Motil 2018;24:43-50.
Financial support: None.

Conflicts of interest: None.

Author contributions: Kyoungwon Jung drafted and edited the manuscript; and Moo In Park revised and performed the final approval. 